\title{
Discrimination of features and orientations of schematic faces by children
}

\author{
FRANK S. MURRAY and PAULA KAY McGUINN \\ Randolph-Macon Woman's College, Lynchburg, Virginia 24503
}

\begin{abstract}
Schematic faces varying in four features (eyes) and four orientations were presented to 46 children ( 10 from nursery school, 18 each from kindergarten and first grade). After familiarization and training on the matching-to-standard procedure, all children received 64 trials, 16 each from four tasks: features, orientations, feature-orientation combinations, and feature-orientation similarities. Results indicate that correct comparisons and response durations were affected by the different features and orientations, and were also related to the complexity of the tasks. Developmental trends were observed in the discriminations of mirror images and in feature-orientation combinations.
\end{abstract}

The effect of orientation on the child's perception of form has long been a subject of controversy in the field of perceptual development. In 1909 Stern reported that young children up to age 7 years ignored the orientation of realistic objects in their verbal recognition of them. $\mathrm{He}$ found that nearly equal responses were given to pictures of people, buildings, toys, and objects of nature, regardless of the orientations in which the pictures were shown. Similar results were reported in later experiments with both realistic objects and geometric figures as stimuli (Arnheim, 1954; Davidson, 1934, 1935; Deich, 1971; Gibson, Gibson, Pick, \& Osser, 1962; Newhall, 1937, Rice, 1930; Vernon, 1957; Wohlwill, 1960). Numerous other studies, however, have shown that orientation is a major factor in perception of both realistic and geometric forms (Braine, 1972; Brooks \& Goldstein, 1963; Ghent, 1960, 1961; Ghent \& Bernstein, 1961; Harris \& Schaller, 1971; Hunton, 1955; Wohlwill \& Wiener, 1964). In addition to orientation, several studies on form perception in children have pointed out the influences of other factors such as: (1) the types and internal features of the materials used as stimuli, (2) the spatial relations of the stimuli in the matching arrays, and (3) the degree of pretraining experiences.

When forms must be discriminated on the basis of internal features and these features are differently oriented, different levels of difficulty are usually experienced. For example, an experiment by Rudel and Teuber (1963) showed that children from 3 to 8 years old had more difficulty with oblique lines than with vertical or horizontal lines in a simultaneous discrimination task. Bryant $(1969,1973)$ reported similar results.

However, the ability to discriminate the internal features of forms must occur at a relatively early age, as attested to by the ability of the infant to recognize his mother's face and distinguish it from other faces (Fagan, 1972; Kagan, 1970). Because of its complexity, the human face is one of the few types of materials that looks different enough to impede recognition when

This work was supported by a grant awarded to the first author from the Mednick Memorial Foundation. The authors would like to express their appreciation for the assistance and cooperation provided to them by the Principal. Sister Seraphim. and the teachers, Janice Ford and Alma Warman, of Villa Maria Academy, and Margaret Sellick of the Randolph-Macon Woman's College Nursery School. rotated $90 \mathrm{deg}$ or more (Rock, 1973). Brooks and Goldstein (1963) reported a direct relation between age (from 3 to 14 years) and the ability to recognize inverted photographs of human faces. Steinfeld (1970) found that the difficulty of recognizing pictures of familiar faces increased as the degree of rotation increased from 45 to 90 to $180 \mathrm{deg}$. Murray and Moon (Note 1) showed that a schematic face is easier to recognize in an upright position than in a rotated one.

Several studies have shown that the spatial relations of the forms in the matching array contribute to the difficulty in form discrimination. There is a tendency to make more errors when reproducing, recognizing, and discriminating between left-right mirror images than up-down mirror images (Davidson, 1934, 1935; Enterline, 1970; Rudel \& Teuber, 1963; Schaller \& Harris, 1974; Sekuler \& Rosenblith, 1964).

It has also been suggested that some of the difficulties that children have in the perception of forms of different orientations may be due to the insufficiencies in the instructions and training provided by the experimenter (Koenigsberg, 1971; Taylor \& Wales, 1970). According to this view, the child is probably able to discriminate the differences among the orientations but may not understand that "different" means different with regard to orientation as well as form and other factors.

The purpose of the present experiment is to examine the factors of features, orientations, and training on the perception of schematic faces by children of different ages.

\section{METHOD}

\section{Subjects}

Fortyeight children of three different age groups participated in the study. Ten children were from the RandolphMacon Woman's College Nursery School (mean age 4 years 8 months), 20 were from the kindergarten (mean age 5 years 8 months), and 18 were from the first-grade class at Villa Maria Academy (mean age 6 years 7 months). Two kindergarten boys were excluded from the study, one because of a failure to meet criterion as stated below and one because of a failure to follow instructions. An equal number of girls and boys completed the experiment, a total of 46 children.

\section{Apparatus and Stimuli}

The stimuli were $35-\mathrm{mm}$ slides projected from a Kodak carousel slide projector (Model 850) on an upright 15-sq-in. 
board $\left(38 \mathrm{~cm}^{2}\right)$. The surface of the board was painted flat black. The slides for familiarization and training were of pictures of objects familiar (e.g., kite, ball, flowers, etc.) to children of the ages tested. The pictures were drawn with black India ink on rectangularly shaped pieces of white cardboard $(7.15 \times 5 \mathrm{~cm})$ and photographed against a black background.

The stimuli used for the experimental trials were slides of schematic faces. These faces were drawn with black India ink on elliptically shaped pieces of heavy white paper. The major and minor axis of the ellipse measured 7.1 and $5 \mathrm{~cm}$, respectively. Four different schematic faces which varied only in the shape of the eye were used (see Figure 1). The nose, drawn along the major axis of the ellipse, was $1.6 \mathrm{~cm}$ long. The top of the nose was $2.9 \mathrm{~cm}$ from the top of the ellipse and the bottom of the nose was $2.5 \mathrm{~cm}$ from the bottom of the ellipse. The mouth was also $1.6 \mathrm{~cm}$ long. The center of the mouth was $1.8 \mathrm{~cm}$ from the bottom of the ellipse. The eyes of the schematic faces were lines $1.2 \mathrm{~cm}$ long. To form four different features of the eye, the line was rotated about its center point, which was $1.3 \mathrm{~cm}$ from the apex of the nose. The eyes of Face $1\left(F_{1}\right)$ were vertical lines drawn parallel to the major axis of the ellipse. The eyes of $F_{2}$ were horizontal lines parallel to the minor axis. $F_{3}$ and $F_{4}$ had oblique lines for eyes. The right eye of $\mathrm{F}_{3}$ was at a 130-deg angle to the minor axis and the left eye was at a 50-deg angle to the minor axis. The eyes of $F_{3}$ appeared to be pointing away from the nose. The right eye of $\mathrm{F}_{4}$ was drawn at a 50-deg angle to the minor axis and the left eye was drawn at a 130-deg angle to the minor axis. The eyes of $\mathrm{F}_{4}$ looked-as if they were pointing to the nose.

\section{Design}

A total of 92 slides was shown to all subjects. Twenty-eight of these slides were employed in the familiarization and training series and the remaining 64 slides were used in the four different tasks. The children were tested on a simultaneous matching-tostandard task in which they were allowed an unlimited time to view the stimuli. The presentation of the slides had been randomized within each series and each child received the same random sequence. The faces within each array were also randomized as to position.

\section{Tasks and Procedures}

The children were taken individually from their classrooms by the experimenter to the experimental room. Each child was told that he or she would be helping with some picture games. The session began with the administration of Kagan's Matching Familiar Figures Test (MFF, preschool set). This test, consisting of 2 practice items and 11 test items, requires the child to point to the picture in an array of four that matches the standard above the array. The child is given feedback concerning the correctness of his response and is asked to continue working on each item until he finds the correct match. All of the child's responses and the duration required to make the first response are recorded.

After the MFF test, the child was shown a series of familiarization and training slides. The child was first asked to name the object shown in four slides. Then four more slides of pairs of these objects were shown to the child. The members of each pair were identical except for orientation. The experimenter asked the child, "Are these two pictures the same or are they different?" If the child correctly responded that they were different, he was asked to explain. If the experimenter was confident that the child had responded on the basis of orienta-

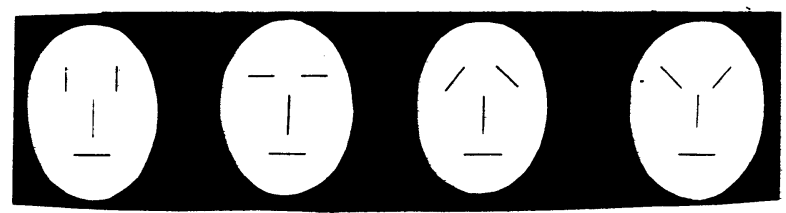

Figure 1. Schematic faces used as stimuli. From left to right, $F_{1}, F_{2}, F_{3}$, and $F_{4}$. tion, the child was praised (e.g., "Good.") and the next slide was shown. If the child replied "Same," the experimenter showed the child how the two pictures pointed in different directions (e.g., "This one is pointing up to the sky but this one is on its side, and the top of it is pointing to the door."). After the first series, each child was told, "When the pictures point in different directions, we will call them different."

The same-different pairs were followed by eight training slides in which the child was asked to point to the picture in an array of four that matched the standard above the array. The instructions were, "Look at the picture at the top and the four pictures at the bottom. Find the picture at the bottom that is the same as the picture at the top. As soon as you see it, point to it." The child was also praised if he was correct; if incorrect, he was asked to try again. If necessary, the experimenter assisted the child. To be sure that the child understood the instructions and was thoroughly familiar with the task, a criterion of at least 8 out of 12 correct responses on the next series of slides was set for all children to continue participating in the experiment. The experimental slides were introduced with the following instructions: "Now we are going to do the same thing except we will be looking at pictures of faces. I want you to point to the face at the bottom that is the same as the face at the top. Point as soon as you see it." The response and duration to each slide was recorded. The experimental series consisted of 64 slides, 16 from each of four different tasks.

Feature (F). In this task the standard and array faces were presented in an upright position $(0 \mathrm{deg})$. The four array faces differed from each other in features and one of the array faces was identical to the standard. Each face was presented as a standard four times.

Orientation (0). Each face was again presented as a standard four times but each time in a different orientation. The standard and array faces had the same features but the array faces differed from each other in orientation. One array face was identical to the standard.

Feature and orientation (FO1 and FO2). In these tasks the faces in the array varied from each other and from the standard in both features and orientations. In the FO1 task, one of the array faces was identical to the standard and the other three faces differed from the standard in either features or orientations. In the FO2 task, one array face matched the standard and the other three faces differed from the standard in both features and orientations. This task should be much less difficult than FO1 becasue of maximum contrast among the stimuli.

Similarity (S). After presenting the 48 slides in a random order from the four tasks above, the 16 similarity slides were presented. This task was similar to the FO tasks, the major difference being that the array did not contain a face identical to the standard. The experimenter presented these instructions, "This time there will not be a face at the bottom that is the same as the one at the top. I want you to point to the face at the bottom that is almost the same as the one at the top, the one that you think looks most like the face at the top." Each of the four faces was presented four times as a standard, each in a different orientation. The array contained one face which matched the standard in features, one in orientation, one in neither feature nor orientation, and one chosen randomly from the 16 possible combinations of features and orientations.

At the end of the experimental session, the child was shown a slide of the four schematic faces at 0 -deg orientation. He was asked to "Point to the face that looks most like a real person's face." This request was made for purposes of determining the face that looked most real to the child. At the conclusion of the experiment, the child was rewarded verbally and with candy.

\section{RESULTS AND DISCUSSION}

The results of this study show that different features and orientations affect children's perception of schematic faces. For all data analyses the total number of 
correct responses and response durations for each task were used as dependent variables.

\section{Feature Task}

Comparison performance on this task was extremely good for all children. Uncertainty-analysis procedures, as described by Hake and Rodwan (1966), were used to evaluate the responses to these stimuli. The amount of reduction in uncertainty, or the amount of association between the stimuli and responses, was highly significant $\left[\chi^{2}(9)=1609.75, \mathrm{p}<.001\right]$.

A factorial analysis of variance for repeated measures on correct comparisons showed that there was a significant difference between responses to the different faces $[F(3,129)=6.07, p<.01]$. The Scheffé procedure for multiple comparisons was used to determine which faces were significantly different from each other. The analyses revealed that $F_{3}$ (mean correct, $\overline{\mathrm{X}}_{\mathrm{C}}=3.5$ ) differed from $F_{1}\left(\bar{X}_{C}=3.8\right)$ and $F_{2}\left(\bar{X}_{C}=3.9\right)$, and none differed from $\mathrm{F}_{4}\left(\overline{\mathrm{X}}_{\mathrm{C}}=3.7\right)$. No differences were obtained among the age groups on the feature task. A significant interaction of Ages by Schematic Faces was obtained $[F(6,129)=2.33, p<.05]$. The most difficult face for all of the children to match was $F_{3}$. This face was especially difficult for the nursery school children, who made, on the average, more correct responses to $F_{1}, F_{2}$, and $F_{4}$ than the kindergarten and first-grade children. There seems to be a relationship between the child's perception of the "realness" of a face and his ease in matching it. When the children were asked which of the four schematic faces looked most like a real person's face, $78.2 \%$ of the children chose $F_{1}$ or $F_{2}$. These two faces were the ones to which the greatest number of correct responses were made.

Analyses of response durations show that first graders responded faster on each trial (mean duration in seconds, $\left.\bar{X}_{D}=4.44\right)$ than kindergarten $\left(\bar{X}_{D}=5.49\right)$ and nursery school $\left(\overline{\mathrm{X}}_{\mathrm{D}}=5.51\right)$ children. These differences were significant $[F(2,43)=3.36, p<.05]$. Response durations to the different faces were also significantly different $[F(3,129)=3.40, p<.05]$. Responding was faster to $F_{1}$ and $F_{2}$ than to $F_{3}$ and $F_{4}$, which supports the analyses of preferences and correct responses to these stimuli.

\section{Orientation Task}

Contingency uncertainty for orientations was 1.5202 bits, which was a highly significant reduction in uncertainty between responses and stimuli $\left[\chi^{2}(9)=\right.$ $1551.09, \mathrm{p}<.001]$. A factorial analysis of variance for repeated measures was again used to determine the effect of orientation. A significant difference between orientations was obtained $[\mathrm{F}(3,129)=3.60, \mathrm{p}<.05]$. The results of the Scheffé procedure for multiple comparisons showed that responses to a schematic face at 0 deg were significantly different from responses to a face at $270 \mathrm{deg}$. A face rotated $270 \mathrm{deg}$ was the most difficult to match. There were no significant differences between the age groups on the task. The interaction of Age Groups by Positions was significant $[F(6,29)=2.33$, $\mathrm{p}<.05]$. The difficulty of matching a standard face at $270 \mathrm{deg}$ was greatest for nursery school children. The kindergarten children made more correct responses than the first graders with all orientations. Again the first graders responded faster to this task than did the kindergarten or nursery school children; the mean durations per trial were $4.46,6.08$, and 5.53 for the three groups, respectively. These differences were also significant $[\mathrm{F}(2,43)=5.13, \mathrm{p}<.01]$.

Of the total number of 57 errors made on the orientation task, $70 \%$ were mirror-image errors. A developmental trend was observed, with nursery school children making a greater number of mirror-image errors $(80 \%)$ than kindergarten $(73 \%)$ or first-grade children $(50 \%)$. As expected, more mirror-image errors were made when the standard was left-right oriented at 90 or $270 \mathrm{deg}$ than when it was at 0 or $180 \mathrm{deg}$; in addition, more left-right mirror-image errors were made when the standard was rotated $270 \mathrm{deg}$ than at $90 \mathrm{deg}$. These results are consistent with those of Davidson (1934) and Braine (1972).

\section{Feature-Orientation Tasks (FO1 and F02)}

The comparative difficulty of matching on FO1 and FO2 tasks was determined with a factorial analysis of variance for repeated measures. It was found that the two tasks were significantly different from each other $[F(1,43)=29.39, p<.01]$. The comparative difficulty of the two tasks was in the expected direction-FO1 $\left(\overline{\mathrm{X}}_{\mathrm{C}}=3.05\right)$ was more difficult than FO2 $\left(\overline{\mathrm{X}}_{\mathrm{C}}=3.79\right)$. This result might be explained by extending Gibson's (1969) prediction of maximal differences for efficiency of discrimination.

A significant difference among the age groups on both FO tasks was obtained. The results of the Scheffé procedure for multiple comparisons revealed a developmental trend. The first graders made significantly more correct responses and required less time to respond than the kindergartners, who made significantly more correct responses than the nursery school children $(\mathrm{p}<.05)$.

\section{Feature, Orientation, and Feature-Orientation Tasks}

A significant difference between these three tasks was obtained $[F(2,86)=16.26, p<.01]$. Scheffé comparisons revealed that the feature-orientation tasks were significantly different in difficulty from the feature and orientation tasks $(p<.05)$. An inspection of the mean number of correct responses on each task shows that the feature-orientation tasks were the most difficult $\left(\overline{\mathrm{X}}_{\mathrm{C}}=3.42\right)$, followed by the orientation $\left(\overline{\mathrm{X}}_{\mathrm{C}}=3.67\right)$ and feature $\left(\overline{\mathrm{X}}_{\mathrm{C}}=3.74\right)$ tasks. A significant interaction of Age Groups by Tasks was also obtained $[F(4,86)=2.56, p<.05]$. The nursery school children made, on the average, more errors on the featureorientation task than kindergarten or first-grade children.

\section{Similarity Task}

On the similarity task the children could respond on the basis of features, orientation, or neither of these. 
A one-way analysis of variance was computed for each of these types of responses to determine if the age groups differed on the basis of their responses. Nursery school children and first graders differed significantly from kindergartners in this task. The nursery school and first-grade children responded on the basis of features $[F(2,43)=6.20, p<.01]$, whereas the kindergarten children responded on the basis of orientations $[F(2,43)=3.99, p<.05]$. Only a small number of responses in each age group were made on the basis of neither features nor orientations. As expected, response durations were greater for this task than all others; mean durations per trial were $5.02,5.26,5.46$, and 6.77 for the feature, orientation, feature-orientation, and similarity tasks, respectively.

\section{Conceptual Style}

The relationship between the duration in seconds to make the first response and the total number of errors on the MFF test for all children was obtained; a small positive correlation was obtained (Cramer's phi contingency, $\phi=.23$ ). No relationship between mean duration of first responses on the MFF- test and the number of errors made on the experimental trials was obtained $(r=.04)$. Children seem to adjust their response durations to the difficulty of the task, and this was borne out in the analyses of response duration to the tasks. The more difficult tasks required more time for decisions by the children, and older children generally required less time than younger children.

\section{REFERENCE NOTE}

1. Murray, F. S., \& Moon, M. S. Effects of features and orientation on the perception of schematic faces in children. Paper presented at the meeting of the Eastern Psychological Association, New York, April 1975.

\section{REFERENCES}

Arnheim, R. Art and visual perception. Berkeley: University of California Press, 1954.

Braine, L. G. A developmental analysis of the effect of stimulus orientation on recognition. American Journal of Psychology, 1972, 85, 157-187.

Brooks, R. M., \& Goldstein, A. G. Recognition by children of inverted photographs of faces. Child Development, 1963, 34, 1033-1040.

BRYANT, P. E. Perception and memory of the orientation of visually presented lines by children. Nature, 1969, 224, 1331-1332.

Bryant, P. E. Perception and memory of orientation of visually presented lines by children. Journal of Comparative and Physiological Psychology, 1973, 82, 415-425.

Davidson, H. P. A study of reversals in young children. Journal of Genetic Psychology, 1934, 44, 452-465.

Davidson, H. P. A study of the confusing letters, B, D, P, and Q. Journal of Genetic Psychology, 1935, 47, 458-468.
DeICH, R. F. Children's perception of differently oriented shapes: Word recognition. Perceptual and Motor Skills, 1971, 32, 695-700.

ENTERLINE, E. J. Form discrimination: Spatial relationships between a standard and comparison figure. Perceptual and Motor Skills, 1970, 30, 956-969.

FAGAN, J. Infants' recognition memory for faces. Journal of Experimental Child Psychology, 1972, 14, 453-476.

GHENT, L. Recognition by children of realistic figures presented in various orientations. Canadian Journal of Psychology, 1960, 14, 249-256.

Ghent, L. Form and its orientation: A child's-eye view. American Journal of Psychology, 1961, 74, 177-190.

GHent, L., \& Bernstein, L. Influence of the orientation of geometric forms on their recognition by children. Perceptual and Motor Skills, 1961, 12, 95-101.

GiBson, E. J. Principles of perceptual learning and development. New York: Appleton-Century-Crofts, 1969.

Gibson, E. J., Gibson, J. J., Pick, A. D., \& Osser, H. A developmental study of the discrimination of letter-like forms. Journal of Comparative and Physiological Psychology, 1962, 55, 897-906.

HAKE, H. W., \& Rodwan, A. S. Perception and recognition. In J. B. Sidowski (Ed.), Experimental methods and instrumentation in psychology. New York: McGraw-Hill, 1966.

Harris, L., \& Schaller, M. J. Form and its orientation: Reexamination of a child's eye view. American Journal of Psychology, 1971, 84, 218-234.

Hunton, V. D. The recognition of inverted pictures by children. Journal of Genetic Psychology, 1955, 86, 281-288.

KAGAN, J. Attention and psychological change in the young child. Science, 1970, 170, 826-832.

KoENIGSBERG, R. S. Evaluation of procedures for improvement of orientation discrimination in preschool children. Proceedings, of the 79th Annual Convention of the American Psychological Association, 1971, 6, 183-184.

Newhall, S. M. Identification by young children of differently oriented forms. Child Development, 1937, 8, 105-111.

RICE, C. The orientation of plane figures as a factor in their perception by children. Child Development, 1930, 1, 111-143.

Rock, I. Orientation and form. New York: Academic Press, 1973.

Rudel, R. G., \& Teuber, H. L. Discrimination of direction of line in children. Journal of Comparative and Physiological Psychology, 1963, 56, 892-898.

SCHALler, M. J., \& HaRRIs, L. Children judge "perspective" transformations of letter-like forms as different from prototypes. Journal of Experimental Child Psychology, 1974, 18, 226-241.

STEINFELd, G. The effect of retinal orientation on the recognition of novel and familiar shapes. Journal of General Psychology, 1970, 82, 223-239.

Sekuler, R. W., \& Rosenblith, J. F. Discrimination of direction of line and the effect of stimulus alignment. Psychonomic Science, 1964, 1, 143-144.

TAYloR, J., \& Wales, R. A developmental study of form discrimination in preschool children. Quarterly Journal of Experimental Psychology, 1970, 22, 720-734.

VERNON, M. D. Backwardness in reading. Cambridge: Cambridge University Press, 1957.

WoHLwill, J. J. Developmental studies of perception. Psychological Bulletin, 1960, 57, 249-288.

Wohlwill, J. F., \& WiEnER, M. Discrimination of form orientation in young children. Child Development, 1964, $35,1113-1125$.

(Received for publication May 3, 1977.) 